\title{
TRPV4 deficiency causes sexual dimorphism in bone metabolism and osteoporotic fracture risk
}

\author{
B.C.J. van der Eerden ${ }^{\text {a,* }}$, L. Oei ${ }^{\text {a,b }}$, P. Roschger ${ }^{c}$, N. Fratzl-Zelman ${ }^{\text {c }}$, J.G.J. Hoenderop ${ }^{\text {d }}$, N.M. van Schoor ${ }^{\text {e }}$, \\ U. Pettersson-Kymmer ${ }^{\text {f }}$, M. Schreuders-Koedam ${ }^{\text {a }}$, A.G. Uitterlinden ${ }^{\text {a,b }}$, A. Hofman ${ }^{\text {b }}$, M. Suzuki ${ }^{g}$, K. Klaushofer ${ }^{\text {c }}$,

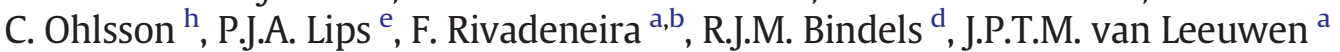 \\ a Department of Internal Medicine, Erasmus MC, Rotterdam, The Netherlands \\ ${ }^{\mathrm{b}}$ Department of Epidemiology, Erasmus MC, Rotterdam, The Netherlands \\ c Ludwig Boltzman Institute of Osteology, Hanusch Hospital of WGKK and AUVA Trauma Centre Meidling, 1st Medical Department, Hanusch Hospital, Vienna, Austria \\ ' Department of Physiology, Nijmegen Centre for Molecular Life Sciences, Radboud University Nijmegen Medical Centre, The Netherlands \\ e Department of Epidemiology and Biostatistics, EMGO Institute for Health and Care Research, VU University Medical Center, Amsterdam, The Netherlands \\ ${ }^{\mathrm{f}}$ Department of Pharmacology and Clinical Neuroscience, Umeå University, Umeå, Sweden \\ ${ }^{g}$ Department of Pharmacology, Jichi Medical School, Tochigi, Japan \\ h Centre for Bone and Arthritis Research, Sahlgrenska Academy, Institute of Medicine, University of Göteborg, Göteborg, Sweden
}

\section{A R T I C L E I N F O}

\section{Article history:}

Received 8 November 2012

Revised 16 August 2013

Accepted 16 September 2013

Available online 29 September 2013

Edited by: R. Baron

\section{Keywords:}

TRPV4

Bone

Osteoporosis

Sexual dimorphism

Fracture risk

\begin{abstract}
A B S T R A C T
We explored the role of transient receptor potential vanilloid 4 (TRPV4) in murine bone metabolism and association of TRPV4 gene variants with fractures in humans. Urinary and histomorphometrical analyses demonstrated reduced osteoclast activity and numbers in male Trpv $4^{-1-}$ mice, which was confirmed in bone marrow-derived osteoclast cultures. Osteoblasts and bone formation as shown by serum procollagen type 1 amino-terminal propeptide and histomorphometry, including osteoid surface, osteoblast and osteocyte numbers were not affected in vivo. Nevertheless, osteoblast differentiation was enhanced in $\operatorname{Trpv} 4^{-1-}$ bone marrow cultures. Cortical and trabecular bone mass was $20 \%$ increased in male $\operatorname{Trp} v 4^{-1-}$ mice, compared to sex-matched wild type $\left(\operatorname{Trp} v 4^{+/+}\right)$ mice. However, at the same time intracortical porosity was increased and bone matrix mineralization was reduced. Together, these lead to a maximum load, stiffness and work to failure of the femoral bone, which were not different compared to $\operatorname{Trp} v 4^{+/+}$mice, while the bone material was less resistant to stress and less elastic. The differential impacts on these determinants of bone strength were likely responsible for the lack of any changes in whole bone strength in the Trpv $4^{-1-}$ mice. None of these skeletal parameters were affected in female $\operatorname{Trp} v 4^{-1-}$ mice.

The T-allele of rs1861809 SNP in the TRPV4 locus was associated with a 30\% increased risk (95\% CI: 1.1-1.6; $\mathrm{p}=0.013$ ) for non-vertebral fracture risk in men, but not in women, in the Rotterdam Study. Meta-analyses with the population-based LASA study confirmed the association with non-vertebral fractures in men. This was lost when the non-population-based studies Mr. OS and UFO were included. In conclusion, TRPV4 is a male-specific regulator of bone metabolism, a determinant of bone strength, and a potential risk predictor for fractures through regulation of bone matrix mineralization and intra-cortical porosity. This identifies TRPV4 as a unique sexually dimorphic therapeutic and/or diagnostic candidate for osteoporosis.
\end{abstract}

(c) 2013 Elsevier Inc. All rights reserved.

\section{Introduction}

The bone is an organ undergoing continuous remodeling, requiring a tight balance between bone resorption (by osteoclasts) and formation (by osteoblasts). The bone stores $99 \%$ of total body $\mathrm{Ca}^{2+}$, making it a vital player in $\mathrm{Ca}^{2+}$ homeostasis. Members of the transient receptor potential (TRP) superfamily, predominantly the transient receptor

\footnotetext{
* Corresponding author at: Department of Internal Medicine, Erasmus MC, room Ee585b, P.O. Box 1738, 3000 DR Rotterdam, The Netherlands. Tel.: + 31107032841; fax: +31107035430 .

E-mail address: b.vandereerden@erasmusmc.nl (B.C.J. van der Eerden).
}

potential vanilloid channels (TRPVs), have been implicated in both $\mathrm{Ca}^{2+}$ homeostasis and bone metabolism. We have demonstrated earlier in mice that the epithelial $\mathrm{Ca}^{2+}$ channel TRPV5 is crucial for renal $\mathrm{Ca}^{2+}$ reabsorption and for proper bone resorption [1,2]. Moreover, mice lacking TRPV6 display disturbed intestinal $\mathrm{Ca}^{2+}$ uptake and reduced bone mass [3-5]. In contrast to TRPV5 and TRPV6, TRPV4 is permeable to $\mathrm{Ca}^{2+}$ in a non-selective manner [6]. TRPV4 responds to a wide variety of stimuli, including hypotonicity, $\mathrm{pH}$, pain, cell swelling, endocannabinoids and mechanical stretching $[7,8]$. Recently, it was shown that activating mutations in the TRPV4 gene leads to several skeletal phenotypes in humans, including several dysplasias of the brachyolmia, spondylometaphyseal, Kozlowski and metatropic types 
$[9,10]$. Two reports have investigated the role of TRPV4 in the murine skeleton but the data obtained are yet inconclusive [11,12]. Although both studies used the same mouse model, one study examined male mice while the other study examined female mice. This may implicate that TRPV4 is a potential driver of skeletal sexual dimorphism such as differences in size and strength [13].

In order to address this, we studied a head-to-head comparison of male and female Trpv $4^{-1-}$ mice with respect to the bone phenotype as well as bone cell differentiation patterns. In addition, we tested genetic variants in the TRPV4 gene locus for association with fracture risk and bone parameters in human cohorts within a meta-analysis.

\section{Material and methods}

Mice, tissue collection and serum/urine analyses

Mice lacking TRPV4 were generated as described extensively [14]. Briefly, cross-breeding of $\mathrm{C} 57 \mathrm{Bl} / 6 \mathrm{TRPV}^{+/+}$and $\mathrm{TRPV}^{-/-}$mice resulted in offspring that were heterozygous for TRPV4. This offspring, bred within the Radboud University Nijmegen Medical Centre animal facility, was inter-crossed to obtain TRPV4 ${ }^{-1-}$ mice. These were subsequently inter-crossed and compared to age-matched TRPV $4^{+/+}$mice. Male and female 20-week-old mice, fed ad libitum, were placed in metabolic cages to collect 24 hour urine. Next, mice were sacrificed and serum was collected. Bones were collected for microcomputed tomography and histomorphometry (left femurs), 3-point bending tests (right femurs) and bone marrow cultures (tibiae). Serum $\mathrm{Ca}^{2+}$ was colorimetrically determined with a $\mathrm{Ca}^{2+}$ assay kit (Sigma, St. Louis, MO, USA) according to the manufacturer's description at $595 \mathrm{~nm}$, using a Bio-Rad microplate reader (Bio-Rad, Hercules, CA, USA). Urinary deoxypyridinoline (DPD) as a marker for bone resorption was analyzed using a MetraDPD enzyme immunoassay (Quidel, San Diego, CA, USA). Serum procollagen type 1 amino-terminal propeptide (P1NP) as a marker for bone formation was measured with an EIA (IDS, Boldon, UK). The animal ethics board of the Radboud University Medical Centre Nijmegen approved all experimental procedures.

\section{Microcomputed tomography $(\mu \mathrm{CT})$}

Femurs from female and male TRPV $4^{+/+}$and TRPV $4^{-/-}$mice $(\mathrm{n}=6)$ were scanned at a resolution of $9 \mu \mathrm{m}$, using a SkyScan 1172 system (Bruker MicroCT, Kontich, Belgium). According to guidelines recently published [15], the following settings were used: X-ray power and tube current were $40 \mathrm{kV}$ and $0.25 \mathrm{~mA}$, respectively. Beam hardening (20\%) was reduced using a $1 \mathrm{~mm}$ aluminium filter, ring-artifacts were reduced (set at 5), exposure time was $5.9 \mathrm{~s}$ and an average of three pictures was taken at each angle $\left(0.9^{\circ}\right)$ to generate final images. Using different software packages from Bruker MicroCT (NRecon, CtAn and Dataviewer), bone microarchitectural parameters were assessed in trabecular and cortical bone of all mice ( $\mathrm{n}=14$ for both genotypes). The trabecular bone parameters trabecular tissue volume, bone volume, trabecular volume fraction (BV/TV), trabecular thickness, trabecular number and trabecular patterning factor (connectivity of trabeculae) were determined in the distal metaphysis of the femur (scan area 0-4 mm of proximal femur). In the mid-diaphysis (scan area 4-6.2 $\mathrm{mm}$ from trochanter), cortical volume, cortical thickness, polar moment of inertia (MOI; proxy for bone strength) and perimeter were analyzed. For image processing, trabecular bone was manually selected and cortical bone was automatically selected. We used a Hamming filter and global thresholding was applied for segmentation, followed by using threshold levels of 150 (lower) and 194 (higher) for trabecular and levels of 0 and 31 for cortical bone measurements. In addition, trabecular and cortical bone mineral density (BMD) was measured on basis of calibration scanning, using two phantoms with known density $\left(0.25 \mathrm{mg} / \mathrm{cm}^{2}\right.$ and $0.75 \mathrm{mg} / \mathrm{cm}^{2}$; Bruker MicroCT) under identical conditions as for the femurs (method note from SkyScan provided on website).

\section{Bone mechanical properties (3-point bending)}

Femurs were stored in phosphate-buffered saline at $-20{ }^{\circ} \mathrm{C}$ until further use. Before the 3-point bending test, femurs were scanned according to the settings mentioned above. The procedure was carried out as previously described in detail [16]. Briefly, femurs were placed in a custom made 3-point bending device, with the loading posts $10 \mathrm{~mm}$ apart. Mechanical testing was performed, using a Single Column Lloyd LRX System (Lloyd Instruments, Fareham, UK). Displacement $(\mathrm{mm})$ and force $(\mathrm{N})$ were registered. Using the same settings for filtration, segmentation and binarization as mentioned above in the microCT section, the MOI, reflecting the ability of the bone to withstand torsion, was calculated using CtAnalyzer software (Bruker MicroCT). It is the integral of the product of the distance between the area of the cortical bone and the center of gravity on one hand and the cortical bone itself on the other. This was determined in the $\mu \mathrm{CT}$ scan-derived crosssection that corresponded to the fracture site resulting from the bending test. From the resulting displacement to force graphs as well as the MOI values, ultimate force $(\mathrm{N})$, stiffness $(\mathrm{N} / \mathrm{mm})$, work to failure $(\mathrm{mJ})$, ultimate stress $\left(\mathrm{N} / \mathrm{mm}^{2}\right.$ ) and elastic modulus ( $\left.\mathrm{GPa}\right)$ were determined as described before [17].

\section{Quantitative backscattered electron imaging}

The distal half of femoral bone samples were fixed in $70 \% \mathrm{v} / \mathrm{v}$ ethanol, dehydrated in ethanol, and embedded in polymethylmethacrylate. Sample blocks containing grinded and polished surfaces of longitudinal femoral sections were manufactured. Bone mineralization density distribution (BMDD) from the trabecular metaphyseal and epiphyseal as well as from the cortical mid-shaft region was determined using quantitative backscattered electron imaging (qBEI). A digital scanning electron microscope (DSM 962, Zeiss, Oberkochen, Germany) operated at an accelerating voltage of $20 \mathrm{kV}$, a probe current of $110 \mathrm{pA}$ and equipped with a four-quadrant semiconductor backscattered electron detector, was used. Images with spatial resolution of $1 \mu \mathrm{m}$ per pixel were acquired for BMDD measurements. This technique is well established and validated and the details of the method have been published elsewhere $[18,19]$. The following BMDD parameters were calculated 1) CaMean is the weighted average Ca concentration of the mineralized tissue area, obtained from the integrated area under the BMDD curve. 2) CaPeak is the peak position of the BMDD histogram showing the most frequently occurring wt.\% Ca of the measured areas. 3) CaWidth is the width at half-maximum of the BMDD histogram curve indicating the heterogeneity of mineralization and 4) CaLow is the percentage of bone area with a calcium concentration of less than 17.68 wt.\% Ca, which reveals the amount of bone area undergoing primary mineralization; and CaHigh, the portion of bone area with a calcium concentration higher than 25.30 wt.\% Ca.

\section{Bone histomorphometry}

After excision, femurs were routinely embedded in methylmetacrylate as described before [2]. Sections of $6 \mu \mathrm{m}$ were subjected to tartrate-resistant acid phosphatase (TRAP) staining. Sections were deacrylated, hydrated and rinsed in $0.2 \mathrm{M}$ sodium acetate $/ 50 \mathrm{mM}$ tartaric acid for $5 \mathrm{~min}$. Naphtol AS-MX $(0.5 \mathrm{mg} / \mathrm{ml})$ and $1.1 \mathrm{mg} / \mathrm{ml}$ Fast red TR salt (both from Sigma, St. Louis, MO, USA) were added and incubated for $120 \mathrm{~min}$ at $37{ }^{\circ} \mathrm{C}$. Counterstaining was performed with haematoxylin for $5 \mathrm{~s}$ and after air-drying, the sections were embedded in Permount (Thermo Fischer Scientific, Waltham, MA, USA). For osteoid measurements, a von Kossa staining was used. After incubation with $2 \% \mathrm{w} / \mathrm{v}$ silver nitrate (ICN Biomedicals, Irvine, CA, USA) for $5 \mathrm{~min}$ in daylight, the sections were counterstained with eosin. The sections were dehydrated and embedded in Entellan (Electron Microscopy Sciences, Hatfield, PA, USA). Eosin-stained osteoid was specifically visualized, using fluorescent imaging with a $365 \mathrm{~nm}$ excitation/420 nm 
emission filter. For osteoblast and osteocyte measurements, sections were stained with a Goldner staining as described before [20].

Images were taken from the TRAP and Goldner stainings with a Nikon Eclipse E400 system (Nikon, Lijnden, the Netherlands) and a Zeiss Axiovert 200 MOT system (Carl Zeiss BV, Jena, Germany) was used for osteoid stainings. Measurements were performed, using the software package Bioquant (Version 7.20; Bioquant image analysis corporation, Nashville, Tennessee, USA).

\section{Quantitative PCR analysis (Q-PCR)}

RNA isolation, cDNA syntheses, and Q-PCR were performed as described previously [21]. Primer and probe sequences and concentrations used for Q-PCR are listed in Supplementary Table 1.

\section{Bone marrow cultures}

Bone marrow cells derived from TRPV $4^{+/+}$and TRPV4 ${ }^{-/-}$mice directed towards osteoclasts and osteoblasts were cultured as described in detail [2,22]. After 6 days of culture, TRAP and coomassie brilliant blue stainings were used to stain for osteoclasts and resorption pits on bone slices left behind by osteoclasts, respectively [2]. Osteoclast number and resorption surface were measured as well as resorption surface per osteoclast, using the freely available ImageJ software (version 1.41; http://rsbweb.nih.gov/ij/). Alkaline phosphatase and alizarin red staining were performed on osteoblast cultures at days 9 and 21 of culture, respectively, as described earlier [2]. Colony numbers and mineralized area were quantified using Bioquant.

\section{Genetic association studies in humans}

To evaluate the effect of genetic variants in TRPV4 on bone outcomes we first focused on the Rotterdam Study where deep phenotyping on bone parameters is available followed by replication assessment of fracture outcomes in three additional studies.

\section{Rotterdam Study}

Individuals were derived from the Rotterdam Study ( $\mathrm{n}=7983$ ), a single-center prospective population-based cohort study of determinants of disabling chronic diseases in the elderly. The Medical Ethics Committee of Erasmus University Medical School approved the Rotterdam Study, and participants provided written informed consent. Both the rationale and the design of the study have been extensively described previously $[23,24]$. In brief, the Rotterdam Study was designed in the mid-1980s as a response to the demographic changes that were leading to an increase of the proportion of elderly people in most populations. It was clear that this would produce a strong rise in elderly people living with diseases, as most diseases cluster at the end of life, and that to discover the causes of diseases in the elderly one would have to study the risk factors of those diseases. The design of the Rotterdam Study is that of a prospective cohort study among, initially, 7983 persons living in the well-defined Ommoord district in the city of Rotterdam in The Netherlands (78\% of 10,215 invitees). They were all 55 years of age or over and the oldest participant at the start was 106 years. The participants were all examined in some detail at baseline. They were interviewed at home and then had an extensive set of examinations in a specially built research facility in the center of their district. These examinations focussed on possible causes of invalidating diseases in the elderly in a clinically state-of the-art manner, as far as the circumstances allowed. The emphasis was put on imaging (of heart, blood vessels, eyes, skeleton and later brain) and on collecting bodily fluids that enabled further in-depth molecular and genetic analyses.

Height and weight were measured in a standing position wearing indoor clothing without shoes. BMI was computed as weight in kilograms divided by height in meters squared $\left(\mathrm{kg} / \mathrm{m}^{2}\right)$. During the home interview, female participants were asked to recall their age at menopause, and responses were validated as described previously [25]. Assessment of vertebral fracture, incident non-vertebral fractures, bone mineral density (BMD) and bone geometry measurements has been described in detail previously [26]. In short, fractures where derived from general practitioner records and validated by two trained physicians. BMD and hip structural analysis measurements were derived from DXA scans acquired with a GE_Lunar DPX-L scanner.

\section{TRPV4 SNP genotyping}

Markers present in the TRPV4 gene region of interest (chromosome 12q24, positions $108,705,277$ to $108,755,595)$ plus $50 \mathrm{~kb}$ up- and downstream of the gene (HapMap release 27, February 2009) were extracted from Illumina HumanHap $550 \mathrm{~K}$ beadchip arrays as described earlier [27] and included 32 haplotype tagging SNPs. These cover most of the common genetic variance in the TRPV4 region spanning chromosome 12 positions 108623000 to 108801400 and including 78 markers. Markers were excluded if: a) they deviated significantly from HardyWeinberg equilibrium $\left(\mathrm{p}<1 \times 10^{-4} ; \mathrm{n}=0\right)$, b) the low minor allele frequency (MAF) was below $5 \%(n=2)$, or c) they had a call rate $<95 \%(\mathrm{n}=3$ ). The exclusion of 5 tagging markers due to low minor allele frequency or genotyping call rate did not substantially affect coverage in the region as only 3 additional markers would be missed. This resulted in 27 SNPs from the Illumina array in the TRPV4 locus area available for gene-wide association analyses, using PLINK v1.05 (Supplementary Fig. 1 and Supplementary Table 2). Genomic control was used to correct for potential population stratification using genome-wide data [28]. The genomic inflation factor (based on median chi-squared) ranged between 1.015 (non-vertebral fracture) and 1.049 (femoral neck BMD) across all bone trait analyses providing evidence against the presence of significant population stratification affecting the results.

\section{Association analysis}

Association of the rs1861809 SNP with bone mineral density (BMD; femoral neck and lumbar spine BMD) were analyzed. Furthermore, association with osteoporotic, non-vertebral, fragility, hip, wrist and vertebral fracture risk as well as hip structural parameters, including narrow neck (NN) width, NN cortical thickness (Ct.Th), NN crosssectional moment of inertia (CSMI) and NN buckling ratio (BR) was assessed.

\section{Replication cohorts}

For replication, men and women from the prospective populationbased cohort study LASA (Longitudinal Aging Study Amsterdam, $\mathrm{n}=904)$, the prospective study MrOS Sweden $(\mathrm{n}=2829)$ and the nested case-control study UFO (Umeå Fracture and Osteoporosis, $n=2807$ ) cohorts were genotyped for rs1861809, the most significantly associated marker in the Rotterdam Study using TaqMan Allele discrimination assay (Applied Biosystems, Nieuwerkerk a/d IJssel, the Netherlands) and included in the analysis. The Longitudinal Aging Study Amsterdam (LASA) is an ongoing multidisciplinary cohort study in older persons. A random sample of men and women aged 55 years and over, stratified by age, sex, urbanization grade and expected 5-years mortality rate was drawn from the population register of Amsterdam, The Netherlands [29]. Follow-up time of the fractures was 6 years. The Osteoporotic Fractures in Men (MrOS) study is a multicenter, prospective study including elderly men. Study subjects (men aged 69-80 years) were randomly identified using national population registers, contacted and asked to participate. Eligible subjects had to be able to walk without assistance, provide self-reported data, and sign an informed consent. For this study data from the MrOS Sweden cohort was used [30]. Assessments of incident fractures have been described before [31]. The UFO study is a nested case-cohort study investigating associations between genes, lifestyle and osteoporotic fractures (average age 65 years of age). The study is based on the prospective and 
population-based Northern Sweden Health and Disease Study cohort, initiated to assess risk factors for diabetes and cardiovascular disease [32,33].

\section{Statistical analyses}

If not stated otherwise, SPSS 15.0 (SPSS, Chicago, IL, USA) was used for the statistical analyses. In all non-genetic experiments values were expressed as mean \pm SEM unless stated otherwise. Differences between groups were tested for significance using the Student-t-test. Baseline parameters and bone geometric data from the genetic studies were expressed as mean \pm SD. Differences between groups were tested for significance using ANOVA. Values were considered significantly different at $\mathrm{p}<0.05$. To estimate the risk of fractures, odds ratios with $95 \%$ confidence intervals $(95 \% \mathrm{CI})$ were calculated using logistic regression models. Trend analysis assuming an underlying additive genetic model was done for the presence of zero, one, or two copies of the associated allele [34]. Since we took only one SNP forward for the replication studies no multiple testing penalty was applied, hence p-values $<0.05$ were considered statistically significant.

\section{Results}

Bone phenotype of male and female Trpv $4^{-/-}$mice

$\mu \mathrm{CT}$ analyses demonstrated a positive effect on bone mass following TRPV4 deficiency in male but not in female mice. Male Trpv $4^{-1-}$ mice displayed increased femoral trabecular (Figs. 1A and B) and cortical (Figs. 1C-E) bone mass compared to female Trpv $4^{+/+}$mice. Femoral bone size was also increased in male $\operatorname{Trpv} 4^{-1-}$ mice as exemplified by larger femoral head volume, diaphyseal volume, perimeter (Figs. 1F-H, respectively) and femoral length (Supplementary Table 3). In females, all parameters described above were unaffected. A summary of these and additional $\mu \mathrm{CT}$ parameters are listed in Supplementary Table 3.

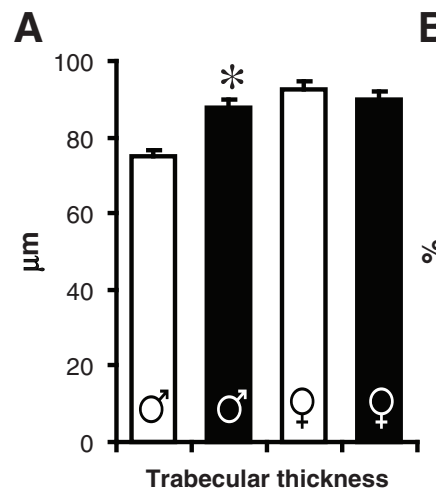

B

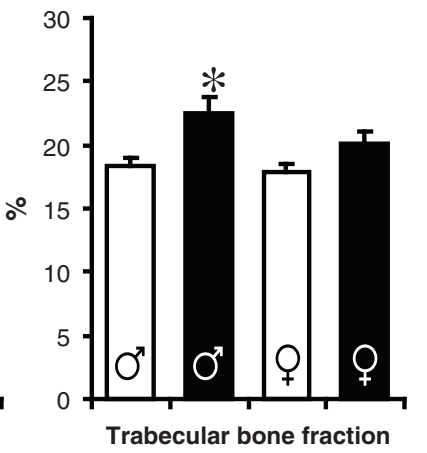

C

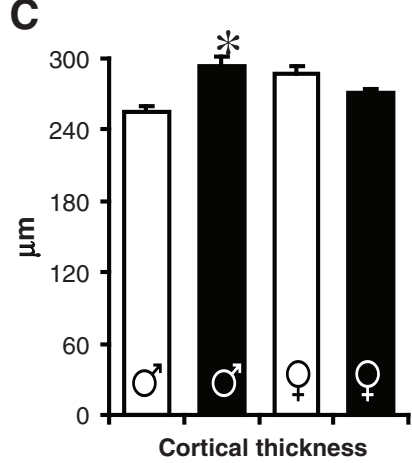

$\mathbf{F}$

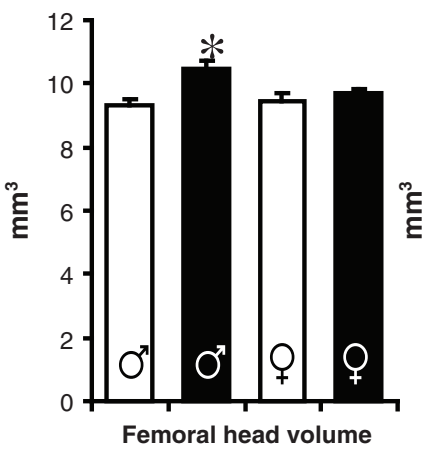

D

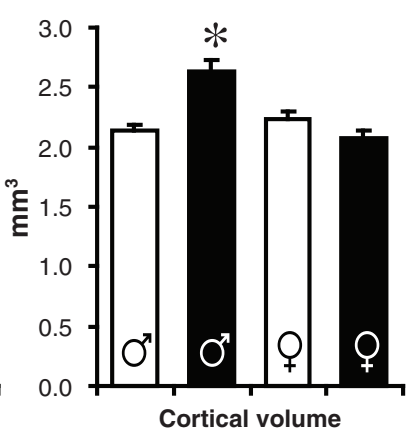

G



E

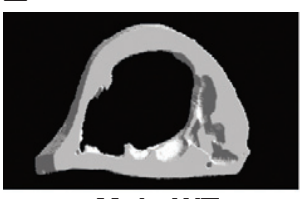

Male WT

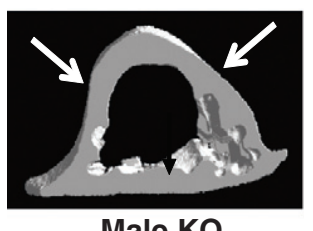

Male KO

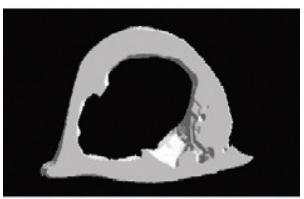

Female WT

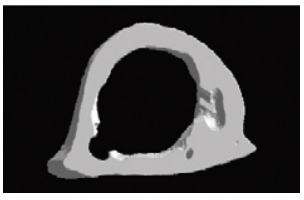

Female KO
H

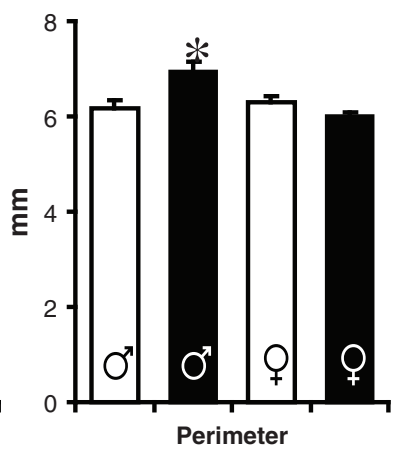

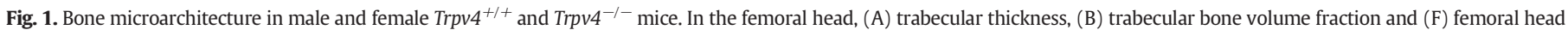

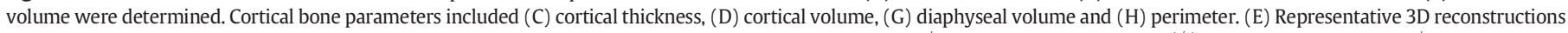

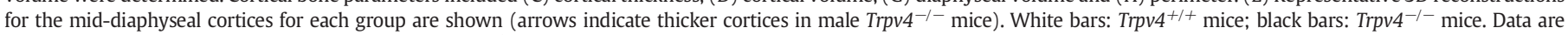
presented as means \pm SEM. ${ }^{*} \mathrm{p}<0.05$ versus male Trpv $4^{+/+}$mice $(\mathrm{n}=6)$. 
We first studied osteoclast function in these Trpv $4^{-1-}$ mice. Urinary DPD analysis showed reduced bone resorption in male Trpv4 ${ }^{-/-}$mice compared to $\operatorname{Trpv} 4^{+/+}$(Fig. 2A). Histomorphometrical analyses of TRAP staining on bone sections confirmed this (Fig. 2B). In femurs from male Trpv $4^{-1-}$ mice, osteoclast number (Fig. 2C) and surface area resorbed (data not shown) was significantly reduced. In contrast, no differences in bone resorption and osteoclast number were observed between the female Trpv $4^{+/+}$and $\operatorname{Trpv} 4^{-/-}$mice (Fig. 2A and data not shown).

Bone marrow-derived osteoclast cultures supported the in vivo observations that osteoclast number and resorption is disturbed in male $\operatorname{Trpv} 4^{-1-}$ but not female mice. Fewer osteoclasts developed from male $\operatorname{Trp} v 4^{-1-}$ bone marrow compared to that of Trpv $4^{+/+}$mice (Fig. 2D), which is paralleled by a significantly reduced resorption surface area (Fig. 2E). Resorption surface per osteoclast analyses demonstrated that osteoclast activity from Trpv $4^{-1-}$ cultures is impaired (Fig. 2F). None of these differences were found in female Trpv $4^{-1-}$ bone marrowderived osteoclast cultures (e.g. osteoclast numbers: $35.1 \pm 3.3$ versus $29.6 \pm 5.4, \mathrm{p}=0.44$ for female Trpv $4^{+1+}$ versus Trpv $4^{-1-}$ mice).

When osteoclast-osteoblast coupling during bone remodeling is intact, reduced osteoclast function should lead to attenuated osteoblast activity. In male Trpv $4^{-1-}$ mice, bone formation was unaffected despite reduced bone resorption as shown by serum P1NP analyses (Fig. 3A). This is supported by histomorphometrical assessment of bone sections showing no differences in number of osteoblast lining trabecular bone (Fig. 3B), percentage osteoid surface (Fig. 3C) and osteocytes in cortices (Fig. 3D) between male Trpv $4^{+/+}$and Trpv $4^{-1-}$ mice.

While the in vivo findings strongly suggest that osteoblast differentiation and function remain unaffected in $\operatorname{Trpv} 4^{-1-}$ mice, osteoblast differentiation was enhanced in bone marrow cultures. Trpv $4^{-1-}$ osteoblast cultures showed a significant increase in the number of alkaline phosphatase positive colonies (Fig. 3E) as well as elevated $\mathrm{Ca}^{2+}$ deposition, although this did not reach significance (Fig. 3F). Colony size was not affected in cultures from male Trpv $4^{-1-}$ mice $(0.10 \pm 0.02 \mathrm{~mm}$ versus
$0.15 \pm 0.02 \mathrm{~mm}, \mathrm{p}=0.1$ for male Trp $4^{+/+}$mice). TRPV4 may directly affect osteoblast and osteoclast function as it is abundantly expressed in both cell types (Figs. 3G-J). No differences in alkaline phosphatase positive colony numbers and $\mathrm{Ca}^{2+}$ deposition were observed between osteoblast cultures from female $\operatorname{Trp} v 4^{+1+}$ and $\operatorname{Trp} v 4^{-1-}$ mice bone marrow (data not shown).

\section{Resistance to stress and elastic modulus is reduced in male Trpv $4^{-1-}$ mice}

To assess whether increased bone mass led to improved bone strength, 3-point bending tests were performed on femurs from male and female $\operatorname{Trp} v 4^{+/+}$and Trpv $4^{-1-}$ mice (Figs. 4A-E). Maximum load, stiffness and work to failure were not different between $\operatorname{Trpv} 4^{+/+}$and $\operatorname{Trpv} 4^{-1-}$ mice (Figs. 4A-C). Interestingly, the femurs from Trpv $4^{-1-}$ mice were less resistant to stress (Fig. 4D) and less elastic (Fig. 4E). However, polar moment of inertia was increased in the $\operatorname{Trpv4^{-1}}{ }^{-}$mice at the site of fracture (Fig. 4F). None of these differences were seen in bones from female mice (e.g. stress: $87.6 \pm 2.9 \mathrm{GPa}$ versus $75.0 \pm$ 3.4 GPa, $\mathrm{p}=0.31$ for female Trpv $4^{+/+}$versus Trpv $4^{-/-}$mice).

We assessed cortical porosity by quantifying the holes appearing in the cortical bone (Fig. 4G-H). Cortical porosity was more than doubled in the male Trpv $4^{-/-}$mice compared to Trpv $4^{+/+}$mice (Fig. $4 \mathrm{I}$ and Supplementary Table. 3 ). The diameter of these holes varied between 40 and $160 \mu \mathrm{m}$. Increased cortical porosity was not observed in the female mice (Supplementary Table 3). Bone mineral density of the femoral trabecular and cortical compartment was unaltered and slightly but significantly increased, respectively, in the Trpv $4^{-/}$mice (Figs. 4J-K).

Finally, we measured bone mineralization density distribution at three positions in femurs of the male $\operatorname{Trpv} 4^{+1+}$ and $\operatorname{Trpv} 4^{-1-}$ mice (Fig. 5A). The bone matrix of Trpv $4^{-1-}$ mice was significantly lower mineralized compared to $\operatorname{Trp} v 4^{+/+}$mice at all skeletal sites analyzed (metaphysis, epiphysis and corticalis) as shown by the significant reduction of CaMean, CaPeak and CaHigh (Figs. 5B, C and D). The width of the BMDD curve (CaWidth) is not altered indicating that the
A

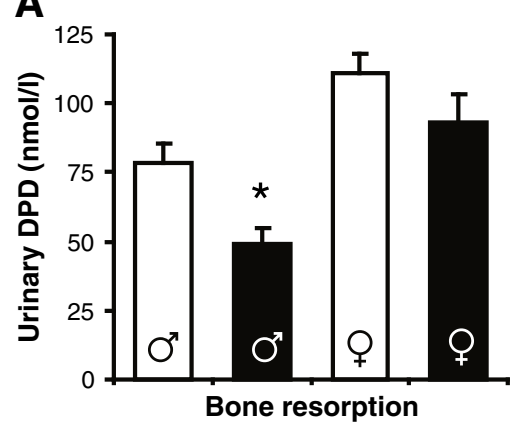

B

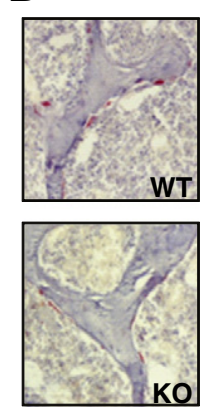

C

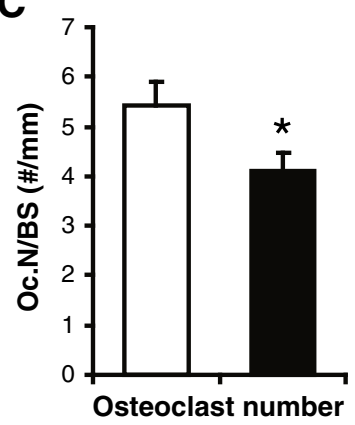

D

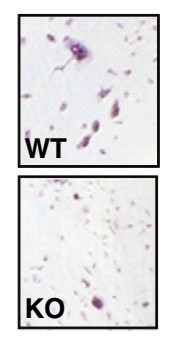

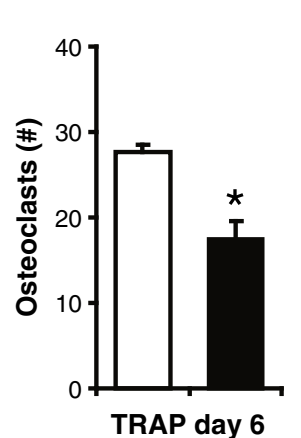

E
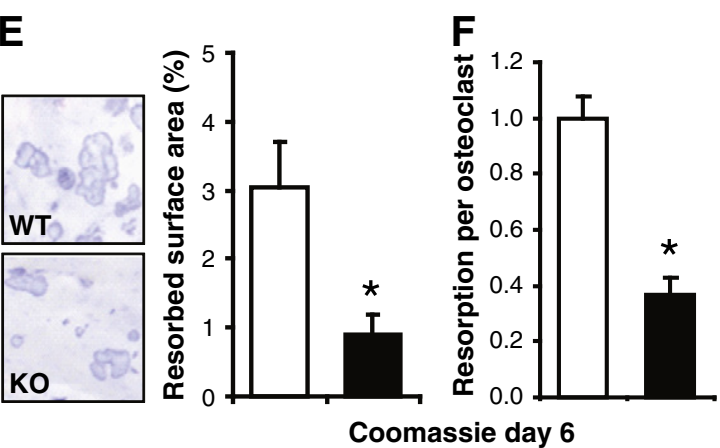

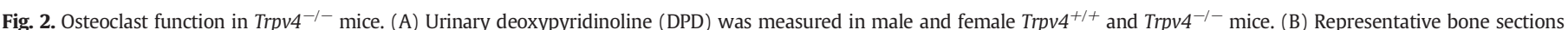

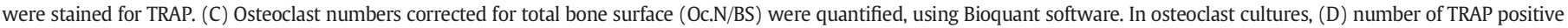

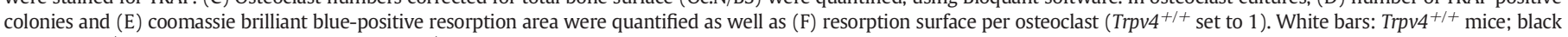
bars: Trpv $4^{-1-}$ mice. ${ }^{*} \mathrm{p}<0.05$ versus male Trpv $4^{+/+}$mice $(\mathrm{n}=6)$. 

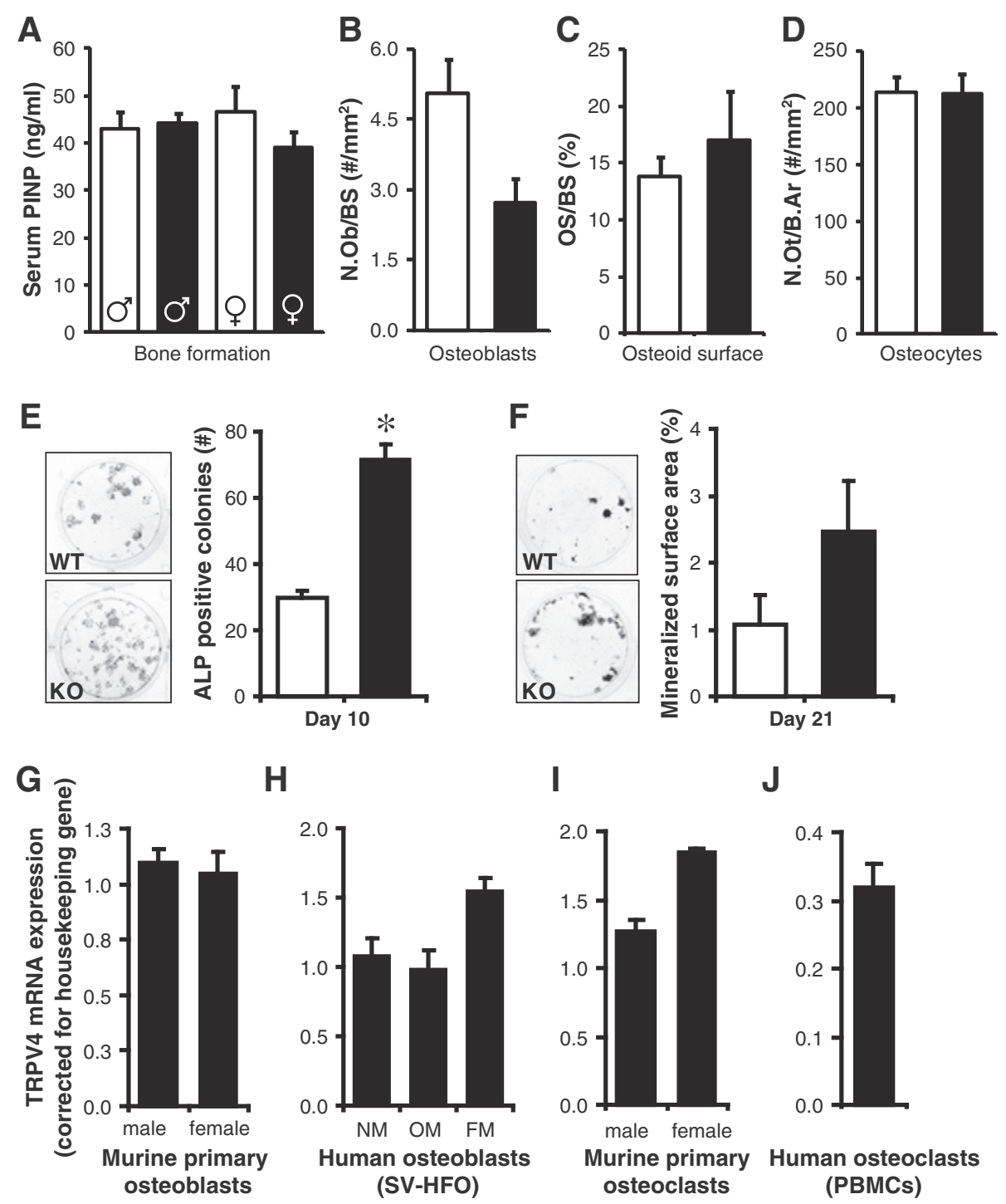

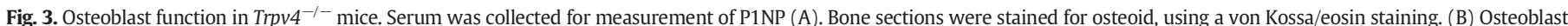

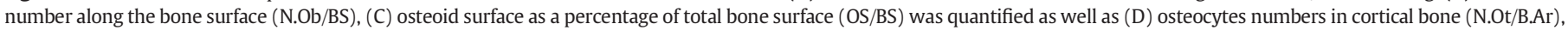

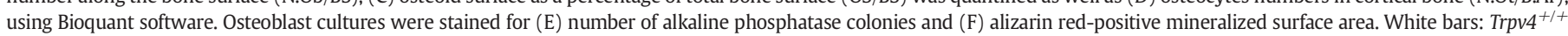

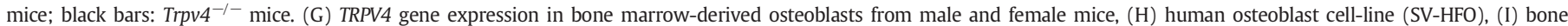

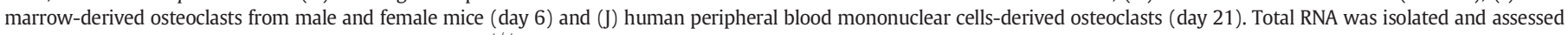
for TRPV4 mRNA expression. ${ }^{*} \mathrm{p}<0.05$ versus male $\operatorname{Trpv} 4^{+/+}$mice $(\mathrm{n}=5)$. Abbreviations: NM, no mineralization; OM, onset of mineralization; FM, full mineralization.

heterogeneity in mineralization is not different between the genotypes (Fig. 5E). The fraction of lowly mineralized bone areas (CaLow), i.e. areas of ongoing bone formation (primary mineralization), in the Trpv $4^{-1-}$ mice is not different from that in Trpv $4^{+/+}$mice (Fig. 5F).

\section{Human genetic association studies on TRPV4 and fracture risk}

We investigated the contribution of TRPV4 to bone phenotypes in humans by studying the association of genetic variants in the TRPV4 gene locus with skeletal phenotypes and fracture risk. Baseline characteristics for the Rotterdam Study population are provided in Supplementary Table 4. Using PLINK software, we tested 27 tagging single nucleotide polymorphisms (SNPs) in the TRPV4 locus for potential association with bone mineral density (BMD), hip geometry and fracture risk in the Rotterdam Study (Supplementary Table 2 and Supplementary Fig. 1) as a discovery cohort. Two intronic tagging SNPs located between exons 2 and 3 of the TRPV4 gene (rs10850783, $\mathrm{C}$ to $\mathrm{A}$, minor allele frequency $=27.4 \%$ and $\mathrm{rs} 1861809$, C to T, $27.3 \%$;
Supplementary Table 2 and Supplementary Fig. 1) were found to be associated with osteoporotic fractures $(p=0.002)$. These SNPs were in complete linkage disequilibrium and so rs 1861809 was chosen for further analyses. No association was observed for rs1861809 with femoral neck and lumbar spine BMD in either men or women (Supplementary Table 5). The hip bone geometric parameters' narrow neck (NN) width and NN cross-sectional moment of inertia (CSMI) were significantly higher in men with the TT genotype $(\mathrm{p}=0.006$ and $\mathrm{p}=0.02$, respectively), but this effect was not observed in women ( $p=0.2$ and 0.14 , respectively; Supplementary Table 5). NN cortical thickness (Ct.Th) and buckling ratio (BR) were not significantly different between the genotypes in either men or women (Supplementary Table 5).

Risk of osteoporotic fractures was 1.9 times higher in men homozygous for the T-allele of rs1861809 (Table 1). Men had a 40\% increased risk for osteoporotic fractures per T-risk allele $(95 \% \mathrm{CI}=1.1-1.7, \mathrm{p}=$ $0.005)$. For fragility and hip fractures the risk was 1.6 times (95\% $\mathrm{CI}=1.1-2.2, \mathrm{p}=0.005$; and $1.1-2.4, \mathrm{p}=0.011$, respectively) higher per risk allele, while for wrist fractures the risk was 2 times (95\% 
A

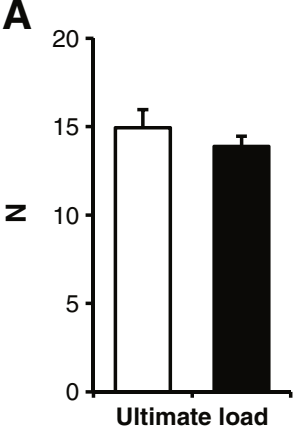

D

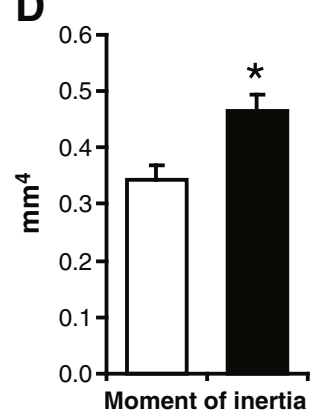

B

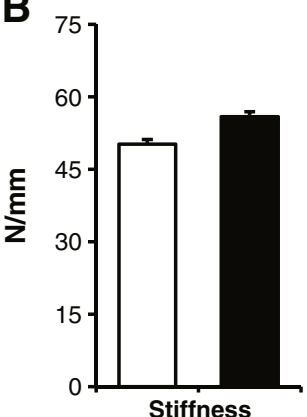

E

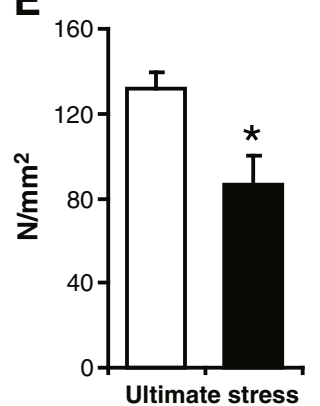

C



$\mathbf{F}$



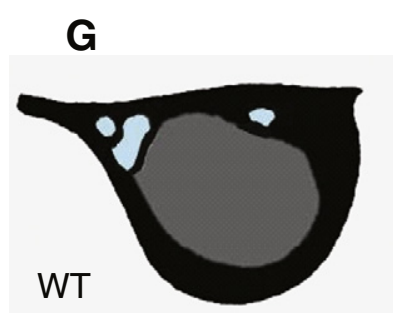
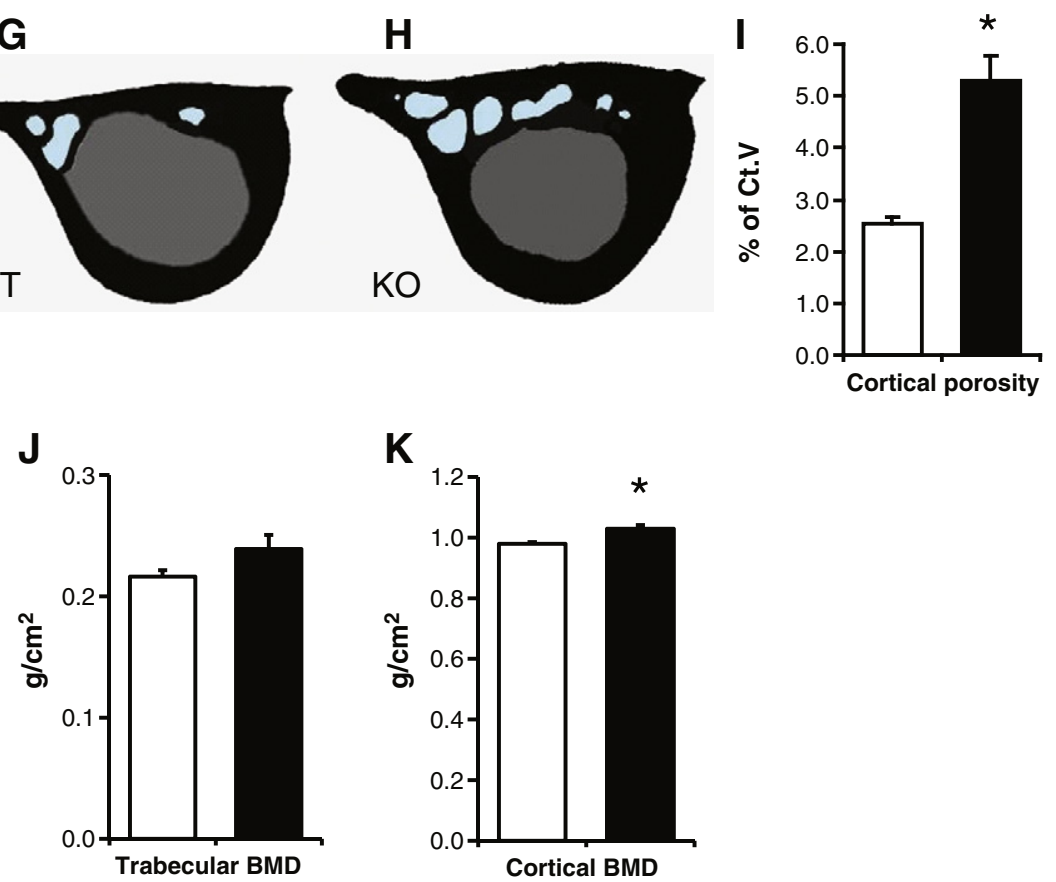



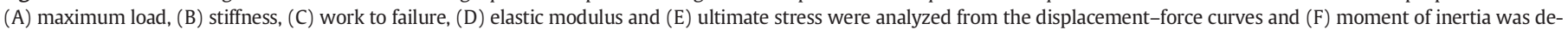

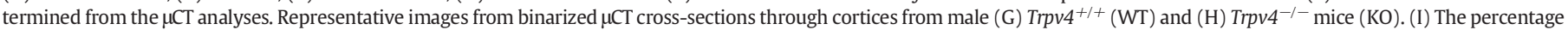

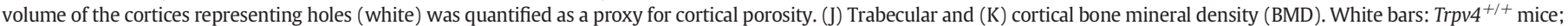
black bars: Trpv $4^{-1-}$ mice. ${ }^{*} \mathrm{p}<0.05$ versus male Trpv $4^{+/+}$mice $(\mathrm{n}=5)$.

$\mathrm{CI}=1.1-3.5, \mathrm{p}=0.014$ ) higher per risk allele. In contrast to men, no association with any type of fracture was observed for women (Table 1).

Next, we sought replication of our genetic associations in other cohorts, including LASA, MrOS and UFO (baseline characteristics in Supplementary Tables 6 and 7). In men from the LASA study the same trend for increased risk for osteoporotic fracture was observed in carriers of the $\mathrm{T}$-allele $(\mathrm{OR}=1.5,95 \% \mathrm{CI} 0.9-2.5, \mathrm{p}=0.11)$ (Supplementary Table 8). Meta-analyses of the Rotterdam and LASA studies together were consistent with a $40 \%$ increase in risk for osteoporotic fracture $(\mathrm{OR}=1.4, \mathrm{CI}=1.1-1.7, \mathrm{p}=0.001$ ) per risk allele (Fig. 6). However, in the Swedish MrOS and UFO studies, no evidence for association with osteoporotic fracture risk was observed in either study. (Supplementary Table 8 and Fig. 6 ). In the meta-analysis, including all four cohorts, the association of the polymorphism with osteoporotic fracture was lost for men ( $\mathrm{OR}=1.1, \mathrm{CI}=1.0-1.3, \mathrm{p}=0.167$; Fig. 6). As expected, for women the association with osteoporotic fractures 
A
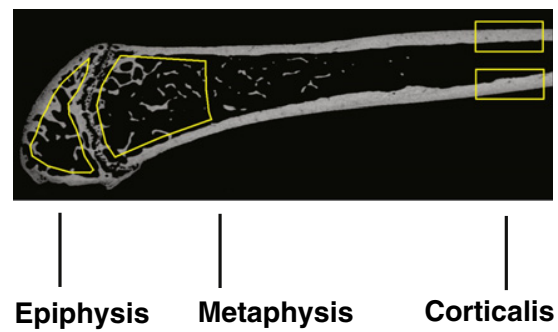

Epiphysis

Metaphysis
CaHigh

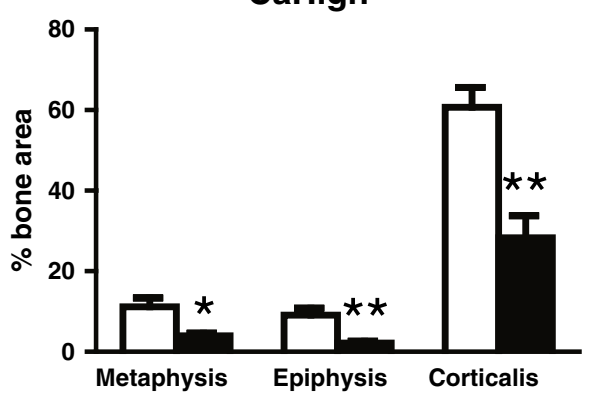

B

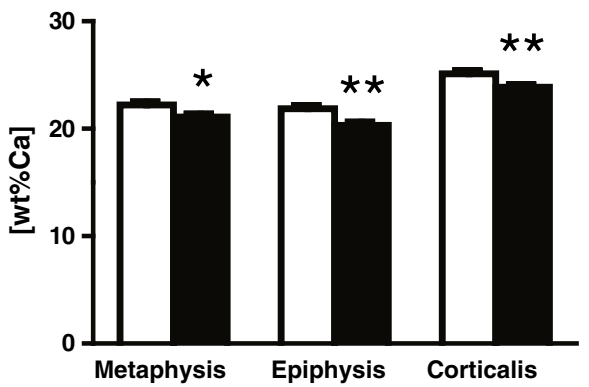

E

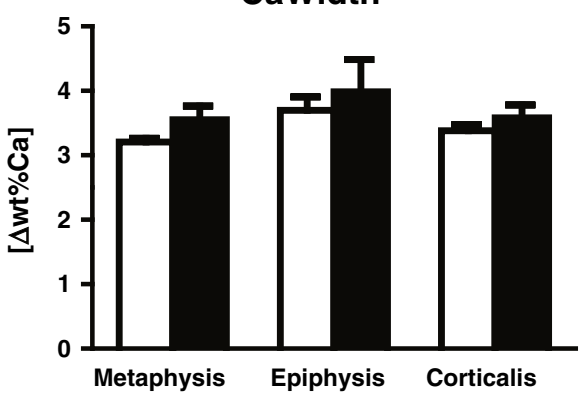

C

CaPeak

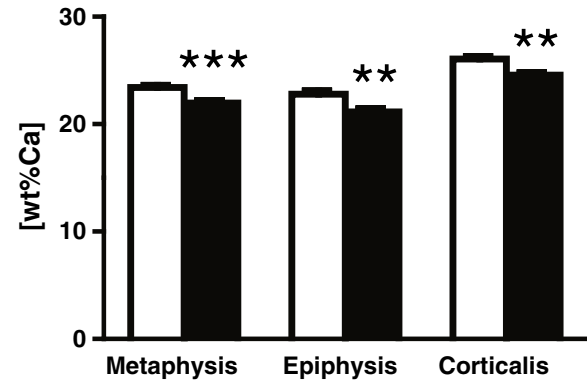

$\mathbf{F}$

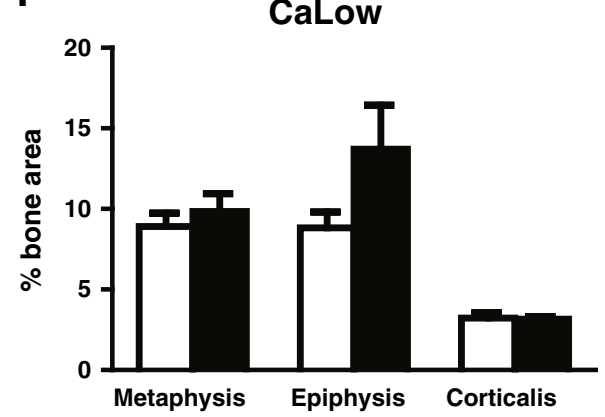

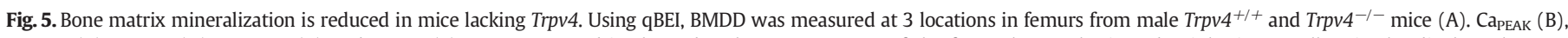

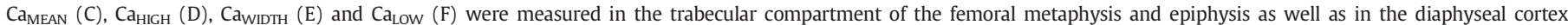
(corticalis). Data are presented as means \pm SEM. ${ }^{*} \mathrm{p}<0.05$ versus $\operatorname{Trp} v 4^{+/+}$controls $(\mathrm{n}=6)$.

remained absent $(\mathrm{OR}=1.0, \mathrm{CI}=0.9-1.0, \mathrm{p}=0.303$; Fig. 6) nor were any signification associations found for other types of fractures (data not shown).

\section{Discussion}

In this multidisciplinary study, using Trpv $4^{-/-}$mice, ex vivo cell biological analyses and genetic association data from human cohorts, we demonstrate that TRPV4 is an important sexually dimorphic factor for determining bone strength, with potentially clinically relevant implications at the population level.

Male Trpv $4^{-1-}$ mice display reduced osteoclast function and osteoclast-osteoblast uncoupling

TRPV4 deficiency leads to an increased bone mass phenotype in male, but not in female mice. This predominantly results from decreased osteoclast formation/differentiation and activity, which has

Table 1

Fracture risks in the Rotterdam Study population for rs1861809.

\begin{tabular}{|c|c|c|c|c|c|c|c|c|}
\hline \multirow[b]{2}{*}{ Trait } & \multirow[b]{2}{*}{$\mathrm{CC}$} & \multicolumn{4}{|l|}{ Men } & \multicolumn{3}{|l|}{ Women } \\
\hline & & $\mathrm{CT}$ & $\mathrm{TT}$ & Trend & $\mathrm{CC}$ & $\mathrm{CT}$ & $\mathrm{TT}$ & Trend \\
\hline \multicolumn{9}{|l|}{ Non-vertebral fractures } \\
\hline $\begin{array}{l}\text { No. fractures/total no. } \\
(\%)\end{array}$ & $\begin{array}{l}46 / 675 \\
(6.8 \%)\end{array}$ & $\begin{array}{l}113 / 1176 \\
(16.7 \%)\end{array}$ & $\begin{array}{l}54 / 498 \\
(20.0 \%)\end{array}$ & 0.013 & $\begin{array}{l}207 / 951 \\
(21.7 \%)\end{array}$ & $\begin{array}{l}331 / 1672 \\
(19.8 \%)\end{array}$ & $\begin{array}{l}152 / 703 \\
(21.7 \%)\end{array}$ & 0.785 \\
\hline $\mathrm{OR}(95 \% \mathrm{CI})$ & 1 & $1.5(1.0-2.1)$ & $1.7(1.1-2.5)$ & & 1 & $0.9(0.7-1.1)$ & $1.0(0.8-1.3)$ & \\
\hline \multicolumn{9}{|l|}{ Osteoporotic fractures } \\
\hline $\begin{array}{l}\text { No. fractures/total no. } \\
(\%)\end{array}$ & $\begin{array}{l}41 / 675 \\
(6.1 \%)\end{array}$ & $\begin{array}{l}89 / 1176 \\
(7.6 \%)\end{array}$ & $\begin{array}{l}53 / 498 \\
(10.6 \%)\end{array}$ & 0.005 & $\begin{array}{l}199 / 951 \\
(20.9 \%)\end{array}$ & $\begin{array}{l}319 / 1672 \\
(19.1 \%)\end{array}$ & $\begin{array}{l}145 / 703 \\
(20.7 \%)\end{array}$ & 0.983 \\
\hline $\mathrm{OR}(95 \% \mathrm{CI})$ & 1 & $1.3(0.9-1.9)$ & $1.9(1.2-2.8)$ & & 1 & $0.9(0.7-1.1)$ & $1.0(0.8-1.3)$ & \\
\hline \multicolumn{9}{|l|}{ Fragility fractures } \\
\hline $\begin{array}{l}\text { No. fractures/total no. } \\
(\%)\end{array}$ & $\begin{array}{l}15 / 675 \\
(2.2 \%)\end{array}$ & $\begin{array}{l}41 / 1176 \\
(3.5 \%)\end{array}$ & $\begin{array}{l}26 / 498 \\
(5.2 \%)\end{array}$ & 0.005 & $\begin{array}{l}84 / 951 \\
(8.8 \%)\end{array}$ & $\begin{array}{l}130 / 1672 \\
(7.8 \%)\end{array}$ & $\begin{array}{l}63 / 703 \\
(9.0 \%)\end{array}$ & 0.968 \\
\hline OR $(95 \% \mathrm{CI})$ & 1 & $1.6(0.9-3.0)$ & $2.5(1.3-4.8)$ & & 1 & $0.9(0.6-1.2)$ & $1.0(0.7-1.5)$ & \\
\hline \multicolumn{9}{|l|}{ Hip fractures } \\
\hline $\begin{array}{l}\text { No. fractures/total no. } \\
(\%) \\
\text { OR }(95 \% \mathrm{CI})\end{array}$ & $\begin{array}{l}11 / 675 \\
(1.6 \%) \\
1\end{array}$ & $\begin{array}{l}27 / 1176 \\
(2.2 \%) \\
1.4(0.7-2.9)\end{array}$ & $\begin{array}{l}20 / 498 \\
(4.0 \%) \\
2.6(1.2-5.6)\end{array}$ & 0.011 & $\begin{array}{l}52 / 951 \\
(5.5 \%) \\
1\end{array}$ & $\begin{array}{l}83 / 1672 \\
(5.0 \%) \\
0.9(0.6-1.3)\end{array}$ & $\begin{array}{l}39 / 703 \\
(5.6 \%) \\
1.1(0.7-1.6)\end{array}$ & 0.886 \\
\hline \multicolumn{9}{|l|}{ Wrist fractures } \\
\hline $\begin{array}{l}\text { No. fractures/total no. } \\
(\%)\end{array}$ & $\begin{array}{l}5 / 675 \\
(0.7 \%)\end{array}$ & $\begin{array}{l}10 / 1176 \\
(0.9 \%)\end{array}$ & $\begin{array}{l}12 / 498 \\
(2.4 \%)\end{array}$ & 0.014 & $\begin{array}{l}62 / 951 \\
(6.5 \%)\end{array}$ & $\begin{array}{l}101 / 1672 \\
(6.0 \%)\end{array}$ & $\begin{array}{l}47 / 703 \\
(6.7 \%)\end{array}$ & 0.942 \\
\hline OR $(95 \% \mathrm{CI})$ & 1 & $1.2(0.4-3.4)$ & $3.3(1.2-9.5)$ & & 1 & $0.9(0.7-1.3)$ & $1.0(0.7-1.5)$ & \\
\hline
\end{tabular}

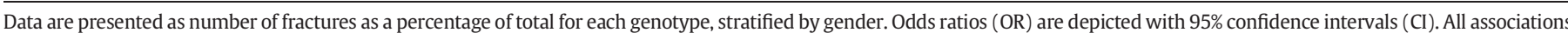
were adjusted for gender, age, height and weight. Trend values represent p-value for an allele-dose effect. 


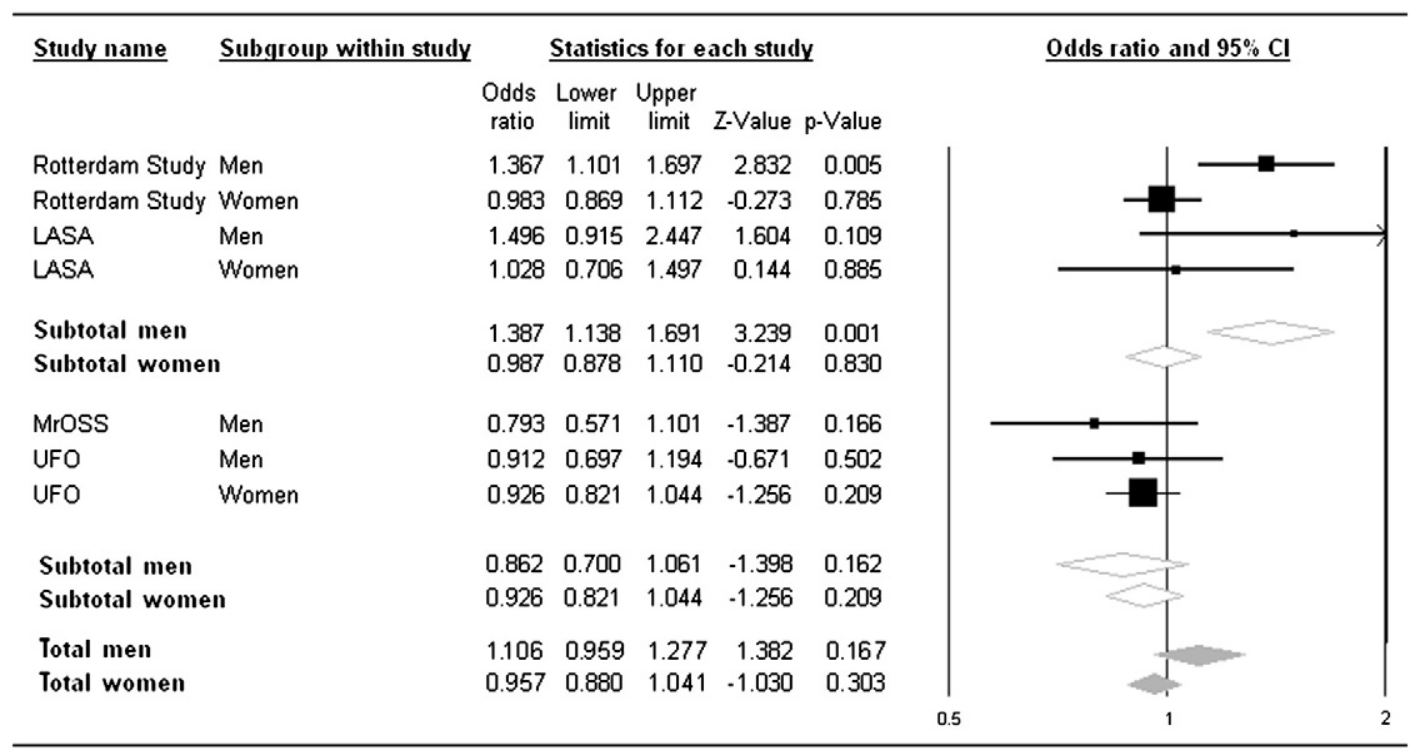

Osteoporotic fracture risk for rs1861089 T vs C allele

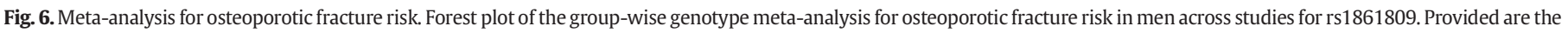
odds ratios for TT versus CC genotype in males and females from the Rotterdam Study, LASA, MrOS Sweden and UFO. All associations were adjusted for age, height and weight.

been demonstrated before $[11,12,35]$. Considering the importance of osteoblast-osteoclast coupling in bone turnover it was anticipated that impaired osteoclast differentiation would lead to reduced osteoblast differentiation. However, bone formation is not affected in the male Trpv $4^{-1-}$ mice in this study, although it is enhanced in ex vivo cultures. This implies that TRPV4 acts indirectly in vivo, through mesenchymal stem cells (MSCs) and limits their differentiation into osteoblasts. TRPV4 is also abundantly expressed on osteoblasts, which suggests a direct effect; the mechanism through which TRPV4 acts on osteoblasts remains elusive. In contrast to our data, it was demonstrated very recently that bone marrow-derived MSCs from Trpv $4^{-1-}$ mice actually were less osteogenic compared to wild type MSCs, whereas the opposite was seen for adipose tissue-derived MSCs [36]. However, these findings are difficult to directly correlate with our data, due to the methodological differences in cell collection (cell sorting), additional passaging of the cells before osteogenic differentiation and culturing under hypoxic conditions, which has been shown to have profound effects on osteogenic differentiation [37]. The reduced bone resorption (DPD as a marker) together with the unchanged bone formation marker (P1NP) demonstrates osteoblast-osteoclast uncoupling following TPRV4 deficiency in male mice only. A summary of the results and a more detailed reasoning for this conclusion is shown in panels 1-6 in Fig. 7. Based on the current data we propose that lack of TPRV4 in male mice, but not female mice, enhances osteoblast development via an osteoblast-intrinsic mechanism (observed: in vitro enhanced osteoblast development; panel 5) that (partially) overrules the in vivo osteoclast-osteoblast coupling signal (observed: in vivo unchanged bone formation; panels 4 and 6) that would have led to reduced osteoblast activity as a consequence of the reduced osteoclast activity and bone resorption (observed: in vivo and in vitro; panels 2 and 6). Overall, these analyses demonstrate a clear sex-specific effect of TRPV4 on bone phenotype, which is due to impaired osteoclast function and disturbed coupling between osteoclasts and osteoblasts.

Male Trpv $4^{-1-}$ mice have increased cortical porosity and reduced matrix mineralization

Despite reduced osteoclast activity, male $\operatorname{Trpv} 4^{-/-}$mice have increased cortical porosity, an important predictor in diagnosing osteoporosis [38]. In fact, non-vertebral fractures at predominantly cortical sites account for $80 \%$ of all fracture age-related osteoporosis [39]. In several mouse models where osteoclast function is increased, such as one where the PTH receptor is constitutively active, or one that overexpresses cathepsin $\mathrm{K}$, intracortical porosity is abundant $[40,41]$. In addition, mice lacking the gastrin receptor Cckbr associated with hypochlorhydria also suffer from increased cortical porosity due to low intestinal $\mathrm{Ca}^{2+}$ absorption and secondary hyperparathyroidism [42]. However, cortical porosity may well arise from insufficient bone remodeling during bone development. For bone remodeling, osteoclast activity is required, which is defective in the male Trpv $4^{-1-}$ mice. An alternative, intriguing explanation is the process of osteocytic osteolysis, a mechanism by which osteocytes are able to resorb their surrounding perilacunar extracellular matrix, which may lead to intracortical porosity (Reviewed in: $[43,44])$. Although osteocyte density was not altered in femoral cortices of our male Trpv $4^{-1-}$ mice (Fig. 3D) the presence of osteocytic osteolysis remains to be established. However, to achieve this yet robust means to quantitatively assess osteocytic osteolysis need to be developed.

The reduction in matrix mineralization in Trpv $4^{-1-}$ mice demonstrates a role for this ion channel in mineralization of bone. The maintenance of cortical bone strength observed in Trpv $4^{-1-}$ male mice despite an increased cortical porosity and the observed reduced bone matrix mineralization can be best explained by a compensatory effect of the increase in bone mass, as reflected by an enhanced moment of inertia. In general, reduced bone matrix mineralization causes a lower ultimate stress and elastic modulus and increased intracortical porosity weakens additionally the mechanical competence of whole cortical bone $[45,46]$. Interestingly, BMD was only slightly increased in these mice. However, taken into account, that a change in BMD has to be considered as the sum of changes in bone volume and bone matrix mineralization [47], it seems that the extent of the increase in bone volume fairly compensated for the increase in porosity and the reduction in bone matrix mineralization in these $\operatorname{Trp} v 4^{-/-}$mice.

The T-allele of rs1861809 is associated with increased fracture risk in men

In the Rotterdam Study we observed that the rs1861809 polymorphism between exons 2 and 3 of TRPV4 harbors BMD-independent sex-specific effects on osteoporotic fracture risk. Our study and others claim that it is crucial to study men and women independently to determine sex-specific genetic factors that contribute to osteoporosis risk 


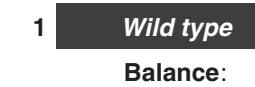

osteoclast - osteoblast coupling

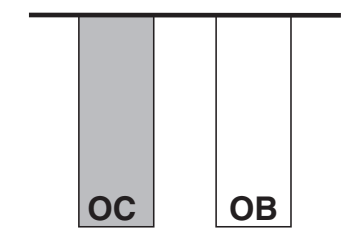

4 TRPV4

Observed: osteoblast /osteocyte number in vivo Observed: bone formation

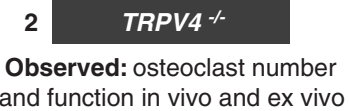

and function in vivo and ex vivo Observed: resorption

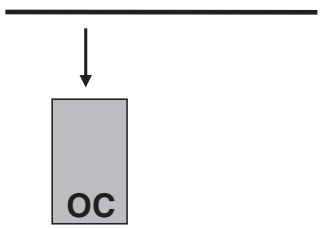

5

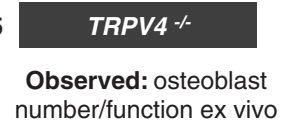

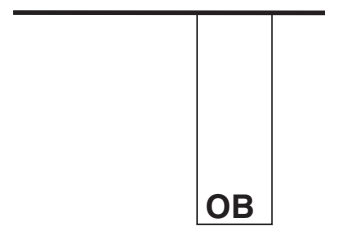

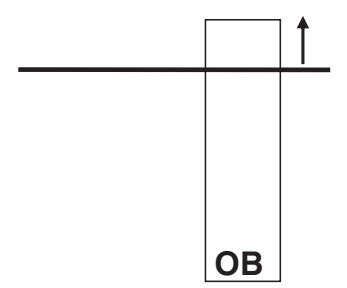

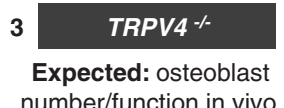

number/function in vivo

Expected: bone formation
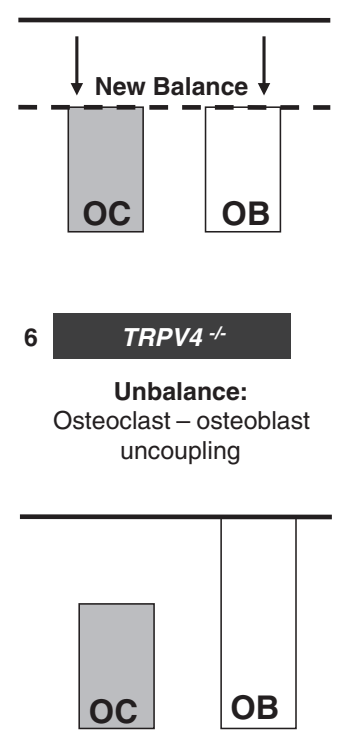

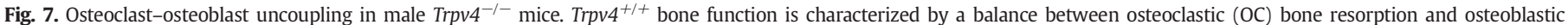

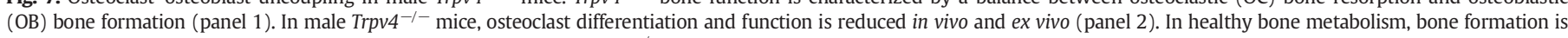

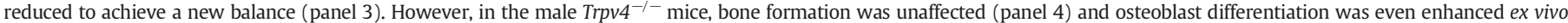

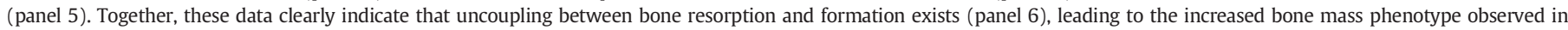
male Trpv4 ${ }^{-1-}$ mice.

[48]. Similarly, it has been proposed that including bone structural parameters can aid the assessment of fracture risk [49-51]. Nevertheless, performing sex-stratified analysis is a limiting approach resulting in a lower power setting.

Male-specific skeletal findings arising from $\operatorname{Trp} v 4^{-1-}$ mice and the ex vivo cell biology analyses were in line with those observed in men from the Rotterdam Study. In addition, including the LASA study (also of Dutch ancestry) resulted in a consistent, albeit smaller, effect estimate, which is most probably a natural consequence of smaller sample size and less power. The association in two additional studies of Swedish origin and lower number of fracture cases did not follow the same trend observed in the studies of Dutch origin. We do not foresee populationspecific effects as allele frequencies of the Rotterdam and LASA studies were similar to those observed in the MrOS Sweden cohort. We did observe different allele frequencies in the UFO cohort as compared to the prospective nature of the other three cohorts, which may be attributable to its case/cohort design. Indeed, having a set of controls enriched with osteoporotic subjects may be an explanation for the observed deviant allele frequencies and also a potential explanation for the lack of association in the UFO cohort. We did not see an effect on BMD but a lower BMD may potentially reflect an enriched set of controls with fracture. Even though the male-specific effect of variants in TRPV4 in relation to fracture was observed in populations of Dutch origin, further scrutiny of these associations in additional prospective cohorts is warranted to confirm potential translation of the effects seen in mice to men.

TRPV4 has been shown to respond to alterations in osmolarity as well as to hypotonicity (reviewed in Cohen et al., 2007). Of interest, we previously demonstrated in the Rotterdam Study that patients with hyponatremia had a $40 \%$ increased risk of getting a non-vertebral fracture [52]. In concordance, others showed a role for hyponatremia in osteoporosis, most likely through activation of osteoclasts [53,54]. Future work should point out whether TRPV4 may be a gateway between hyponatremia and fracture risk in the elderly.
Phenotype consistencies and inconsistencies across species

The consistency between the genetic association data in the Rotterdam and LASA Studies and the findings in the Trpv $4^{-1-}$ mice that bone strength is affected in males but not in females - is striking. An explanation for increased fracture risk in men despite an increase in bone mass may reside in reduced bone matrix mineralization and/ or increased cortical porosity, as was shown in the male mice. Although there are studies describing the assessment of cortical porosity in the distal radius [38], we currently have no bone matrix mineralization and cortical porosity data from the Rotterdam Study to corroborate this hypothesis at the population level. Interestingly, increased midpubertal cortical thickness is associated with an increase in forearm fractures but also with elevated cortical porosity [55], which is more pronounced in boys than in girls [56]. These processes evolve from endocortical bone resorption, most likely due to excess $\mathrm{Ca}^{2+}$ requirements in the growing adolescent $[57,58]$. It is tempting to speculate that this transient 'weakness' of the long bones, in combination with DNA variations in the TRPV4 locus may lead to more permanent alterations in bone structure and/or composition resulting in an increased fracture risk for elderly men. There is recent supporting data that reduction in bone matrix mineralization can contribute to the increased fracture risk in men $[59,60]$.

Childhood fractures may actually better reflect the porosity phenotype we observe in the male $\operatorname{Trp} v 4^{-1-}$ mice, being bone growth related rather than bone loss related, which occurs in the human aging cohorts that we assessed in this study. Although fracture incidence seems to show a bimodal pattern with an increased fracture incidence during puberty, the incidence is still very low compared to that of the elderly population and studies will lack power. With recently initiated population studies such as the Generation $\mathrm{R}$ cohort focusing on children from birth to adulthood [61], we may be able to study childhood fractures in the forthcoming years. 
Dominant mutations in the TRPV4 gene lead to a comprehensive family of bone dysplasia's, ranging from lethal metatotropic dysplasia to familial arthropathy with brachydactyly [62]. The range and severity of the skeletal conditions together with the knowledge that a single mutation in the TRPV4 gene leads to different dysplasias, suggests modulation by other parts of the genome. Despite the human mutations, which so far are all dominant and activating of nature, ablation of the whole gene in murine studies (thereby inactivating the gene) displays a surprisingly mild skeletal phenotype ([11] and our data). Potentially, activating TRPV4 function by introducing the mutations leading to the various human bone dysplasias in a murine setting will phenocopy what we see in man but this requires extensive mouse genetic approaches.

\section{TRPV4 deficiency is sexually dimorphic}

The current study demonstrates a role for TRPV4 in explaining sexual dimorphism in bone metabolism and maintenance of bone strength. The underlying mechanism is unclear and currently purely speculative but other examples of a gender-specific bone phenotype have been described, for example in myeloid-specifically ablated leptin receptor knockout mice [63]. A role for sex steroid hormones such as androgens or estrogens seems logical but there is no data to support an interaction with TRPV4. It has been reported that TRPV4 is expressed in the testes of male rats $[6,64]$ but a relation with sex steroid production has not been shown. Although we cannot fully explain the current sex-specific findings in the Trpv $4^{-1-}$ animals we did find an induction of TRPV4 mRNA expression by $17 \beta$-estradiol in cultured osteoblasts from male, but not female mice, suggesting a difference in sensitivity to sex steroids between males and females. It is worth mentioning that although sex was not mentioned in the majority of the reports describing a phenotype in Trpv4 $4^{-1-}$ mice, the ones that did, actually used male mice in their studies $[11,65,66]$. Of interest, in a recent review it was stated that sex differences also occur in the absence of hormonal changes through sex chromosome-mediated epigenetic regulation of autosomal chromosomes, such as DNA methylation and histone modifications [67].

\section{Conclusion}

In conclusion, TRPV4 is a male-specific determinant of bone strength. TRPV4 influences bone by uncoupling of osteoclast and osteoblast activity and increase in bone mass in a sexually dimorphic manner. In addition, TRPV4 plays a role in bone matrix mineralization, which is reduced, and together with enhanced cortical porosity, may lead to reduced elasticity of bone. The increased bone mass and moment of inertia observed in the male Trpv $4^{-1-}$ mice seem to preserve bone strength, but this compensation mechanism may be lost during aging, potentially leading to reduced bone strength and fracture risk. Finally, the human genetic association analyses, which support a role of TRPV4 in male but not female osteoporosis, need to be replicated and verified.

Supplementary data to this article can be found online at http://dx. doi.org/10.1016/j.bone.2013.09.017.

\section{Acknowledgments}

We would like to thank A. van der Kemp, B. de Hoon and P. Kramer for their technical assistance and Prof. $H$. Weinans for the $\mu \mathrm{CT}$ support. This study was funded by the Erasmus Medical Center, Rotterdam, The Netherlands.

Rotterdam Study

We acknowledge all the participating general practitioners, research physicians, and the many field workers in the research center in Ommoord, Rotterdam, The Netherlands. The authors are very grateful to the contributors of the fracture data set, DXA and research technicians.

LASA

We acknowledge J. Poppelaars from the VU University Medical Center/VU University Amsterdam for providing the LASA cohort data.

\section{MrOS}

In addition, we express our gratitude to Dan Mellström, Magnus Karlsson and Östen Ljunggren for providing the data from the Göteborg, Malmö and Uppsala cohorts of the MrOS Sweden study, respectively.

UFO

We acknowledge the additional investigators in the UFO study group: Göran Hallmans, Olle Svensson and Ulrica Bergström all at Umeå University. We also like to thank Åsa Ågren, Hubert Sjödin and Magnus Hellström for skilful data processing and for help creating the UFO database and Kerstin Enquist and Ann-Marie Åhrén for their help in preparing samples for genotyping. We would also like to thank the participants and staff from the NSHDS cohort study.

Grant supporters

This work was funded by the Erasmus Medical Center, Rotterdam, The Netherlands.

The Rotterdam Study is funded by the Erasmus Medical Center and Erasmus University, Rotterdam; The Netherlands Organization for the Health Research and Development (ZonMw); the Research Institute for Diseases in the Elderly (RIDE); the Ministry of Education, Culture and Science; the Ministry for Health, Welfare and Sports; the European Commission (DG XII); and the Municipality of Rotterdam. Replication of results was conducted within the framework of the GENOMOS and GEFOS consortia, funded by the European Commission (HEALTH-F2-2008-201865, GEFOS). The LASA study was funded by the Dutch Ministry of Health, Welfare and Sports and VU University, Amsterdam.

The MrOS study was supported by the Swedish Research Council, the Swedish Foundation for Strategic Research, the ALF/LUA research grant in Göteborg, and the Lundberg.

Foundation, the Torsten and Ragnar Söderberg's Foundation, and the Novo Nordisk Foundation. The Umeå Fracture and Osteoporosis Study (UFO) is supported by the Swedish Research Council, the Swedish Sports Research Council, the Swedish Society of Medicine, the Kempe-Foundation, and by grants from the Medical Faculty of Umeå University (ALF, VLL) and from the county council of Vasterbotten (Spjutspetsanslag VLL).

\section{References}

[1] Hoenderop JG, van Leeuwen JP, van der Eerden BC, Kersten FF, van der Kemp AW, Merillat AM, et al. Renal Ca2 + wasting, hyperabsorption, and reduced bone thickness in mice lacking TRPV5. J Clin Invest 2003;112:1906-14.

[2] van der Eerden BC, Hoenderop JG, de Vries TJ, Schoenmaker T, Buurman CJ, Uitterlinden AG, et al. The epithelial Ca2 + channel TRPV5 is essential for proper osteoclastic bone resorption. Proc Natl Acad Sci U S A 2005;102:17507-12.

[3] Bianco SD, Peng JB, Takanaga H, Suzuki Y, Crescenzi A, Kos CH, et al. Marked disturbance of calcium homeostasis in mice with targeted disruption of the trpv6 calcium channel gene. J Bone Miner Res 2007;22:274-85.

[4] van der Eerden BC, Weissgerber P, Fratzl-Zelman N, Olausson J, Hoenderop JG, Schreuders-Koedam M, et al. The transient receptor potential channel TRPV6 is dynamically expressed in bone cells but is not crucial for bone mineralization in mice. J Cell Physiol 2012;227:1951-9.

[5] Lieben L, Benn BS, Ajibade D, Stockmans I, Moermans K, Hediger MA, et al. Trpv6 mediates intestinal calcium absorption during calcium restriction and contributes to bone homeostasis. Bone 2010;47:301-8.

[6] Strotmann R, Harteneck C, Nunnenmacher K, Schultz G, Plant TD. OTRPC4, a nonselective cation channel that confers sensitivity to extracellular osmolarity. Nat Cell Biol 2000;2:695-702.

[7] Nilius B. TRP channels in disease. Biochim Biophys Acta 2007;1772:805-12.

[8] Liedtke W. Transient receptor potential vanilloid channels functioning in transduction of osmotic stimuli. J Endocrinol 2006;191:515-23.

[9] Rock M], Prenen J, Funari VA, Funari TL, Merriman B, Nelson SF, et al. Gain-of-function mutations in TRPV4 cause autosomal dominant brachyolmia. Nat Genet 2008;40: 999-1003.

[10] Bellido T, Huening M, Raval-Pandya M, Manolagas SC, Christakos S. Calbindin-D28k is expressed in osteoblastic cells and suppresses their apoptosis by inhibiting caspase-3 activity. J Biol Chem 2000;275:26328-32

[11] Masuyama R, Vriens J, Voets T, Karashima Y, Owsianik G, Vennekens R, et al. TRPV4mediated calcium influx regulates terminal differentiation of osteoclasts. Cell Metab 2008;8:257-65.

[12] Mizoguchi F, Mizuno A, Hayata T, Nakashima K, Heller S, Ushida T, et al. Transient receptor potential vanilloid 4 deficiency suppresses unloading-induced bone loss. J Cell Physiol 2008;216:47-53. 
[13] Callewaert F, Venken K, Kopchick JJ, Torcasio A, van Lenthe GH, Boonen S, et al Sexual dimorphism in cortical bone size and strength but not density is determined by independent and time-specific actions of sex steroids and IGF-1: evidence from pubertal mouse models. J Bone Miner Res 2010;25:617-26.

[14] Suzuki M, Mizuno A, Kodaira K, Imai M. Impaired pressure sensation in mice lacking TRPV4. J Biol Chem 2003;278:22664-8.

[15] Bouxsein ML, Boyd SK, Christiansen BA, Guldberg RE, Jepsen KJ, Muller R. Guidelines for assessment of bone microstructure in rodents using micro-computed tomography. J Bone Miner Res 2010;25:1468-86.

[16] Westbroek I, Waarsing JH, van Leeuwen JP, Waldum H, Reseland JE, Weinans H, et al. Long-term fluoxetine administration does not result in major changes in bone architecture and strength in growing rats. J Cell Biochem 2007;101:360-8.

[17] Turner $\mathrm{CH}$, Burr DB. Basic biomechanical measurements of bone: a tutorial. Bone 1993; 14:595-608.

[18] Roschger P, Paschalis EP, Fratzl P, Klaushofer K. Bone mineralization density distribution in health and disease. Bone 2008;42:456-66.

[19] Roschger P, Fratzl P, Eschberger J, Klaushofer K. Validation of quantitative backscattered electron imaging for the measurement of mineral density distribution in human bone biopsies. Bone 1998;23:319-26.

[20] Gruber HE. Adaptations of Goldner's Masson trichrome stain for the study of undecalcified plastic embedded bone. Biotech Histochem 1992;67:30-4

[21] Eijken M, Hewison M, Cooper MS, de Jong FH, Chiba H, Stewart PM, et al. 11betahydroxysteroid dehydrogenase expression and glucocorticoid synthesis are directed by a molecular switch during osteoblast differentiation. Mol Endocrinol 2005; 19 : 621-31.

[22] de Vries TJ, Schoenmaker T, Beertsen W, van der Neut R, Everts V. Effect of CD44 deficiency on in vitro and in vivo osteoclast formation. J Cell Biochem 2005;94:954-66.

[23] Hofman A, Grobbee DE, de Jong PT, van den Ouweland FA. Determinants of disease and disability in the elderly: the Rotterdam Elderly Study. Eur J Epidemiol 1991;7: 403-22.

[24] Hofman A, van Duijn CM, Franco OH, Ikram MA, Janssen HL, Klaver CC, et al. The Rotterdam Study: 2012 objectives and design update. Eur J Epidemiol 2011;26:657-86.

[25] Weel AE, Uitterlinden AG, Westendorp IC, Burger H, Schuit SC, Hofman A, et al. Estrogen receptor polymorphism predicts the onset of natural and surgical menopause. J Clin Endocrinol Metab 1999;84:3146-50.

[26] Rivadeneira F, van Meurs JB, Kant J, Zillikens MC, Stolk L, Beck TJ, et al. Estrogen receptor beta (ESR2) polymorphisms in interaction with estrogen receptor alpha (ESR1) and insulin-like growth factor I (IGF1) variants influence the risk of fracture in postmenopausal women. J Bone Miner Res 2006;21:1443-56.

[27] Rivadeneira F, Styrkarsdottir U, Estrada K, Halldorsson BV, Hsu YH, Richards JB, et al. Twenty bone-mineral-density loci identified by large-scale meta-analysis of genome-wide association studies. Nat Genet 2009;41:1199-206.

[28] Devlin B, Roeder K. Genomic control for association studies. Biometrics 1999;55: 997-1004.

[29] Huisman M, Poppelaars J, van der Horst M, Beekman AT, Brug J, van Tilburg TG, et al. Cohort profile: the longitudinal aging study Amsterdam. Int J Epidemiol 2011;40: 868-76.

[30] Mellstrom D, Johnell O, Ljunggren O, Eriksson AL, Lorentzon M, Mallmin H, et al. Free testosterone is an independent predictor of BMD and prevalent fractures in elderly men: MrOS Sweden. J Bone Miner Res 2006:21:529-35.

[31] Mellstrom D, Vandenput L, Mallmin H, Holmberg AH, Lorentzon M, Oden A, et al. Older men with low serum estradiol and high serum SHBG have an increased risk of fractures. J Bone Miner Res 2008;23:1552-60.

[32] Hallmans G, Agren A, Johansson G, Johansson A, Stegmayr B, Jansson JH, et al Cardiovascular disease and diabetes in the Northern Sweden Health and Disease Study Cohort - evaluation of risk factors and their interactions. Scand J Public Health Suppl 2003;61:18-24.

[33] Englund U, Nordstrom P, Nilsson J, Bucht G, Bjornstig U, Hallmans G, et al. Physical activity in middle-aged women and hip fracture risk: the UFO study. Osteoporos Int 2011;22:499-505.

[34] Rivadeneira F, Houwing-Duistermaat JJ, Beck TJ, Janssen JA, Hofman A, Pols HA, et al. The influence of an insulin-like growth factor I gene promoter polymorphism on hip bone geometry and the risk of nonvertebral fracture in the elderly: the Rotterdam Study. J Bone Miner Res 2004;19:1280-90.

[35] Masuyama R, Mizuno A, Komori H, Kajiya H, Uekawa A, Kitaura H, et al. Calcium/ calmodulin-signaling supports TRPV4 activation in osteoclasts and regulates bone mass. J Bone Miner Res 2012;27:1708-21.

[36] O'Conor CJ, Griffin TM, Liedtke W, Guilak F. Increased susceptibility of Trpv4deficient mice to obesity and obesity-induced osteoarthritis with very high-fat diet. Ann Rheum Dis 2013;72:300-4.

[37] Nicolaije C, Koedam M, van Leeuwen JP. Decreased oxygen tension lowers reactive oxygen species and apoptosis and inhibits osteoblast matrix mineralization through changes in early osteoblast differentiation. J Cell Physiol 2012;227:1309-18.

[38] Zebaze RM, Ghasem-Zadeh A, Bohte A, Iuliano-Burns S, Mirams M, Price RI, et al. Intracortical remodelling and porosity in the distal radius and post-mortem femurs of women: a cross-sectional study. Lancet 2010;375:1729-36.
[39] Kanis JA, Johnell O, Oden A, Dawson A, De Laet C, Jonsson B. Ten year probabilities of osteoporotic fractures according to BMD and diagnostic thresholds. Osteoporos Int 2001;12:989-95.

[40] Ohishi M, Chiusaroli R, Ominsky M, Asuncion F, Thomas C, Khatri R, et al. Osteoprotegerin abrogated cortical porosity and bone marrow fibrosis in a mouse model of constitutive activation of the PTH/PTHrP receptor. Am J Pathol 2009;174: 2160-71.

[41] Morko J, Kiviranta R, Hurme S, Rantakokko J, Vuorio E. Differential turnover of cortical and trabecular bone in transgenic mice overexpressing cathepsin $\mathrm{K}$. Bone 2005;36:854-65.

[42] Schinke T, Schilling AF, Baranowsky A, Seitz S, Marshall RP, Linn T, et al. Impaired gastric acidification negatively affects calcium homeostasis and bone mass. Nat Med 2009;15:674-81.

[43] Teti A, Zallone A. Do osteocytes contribute to bone mineral homeostasis? Osteocytic osteolysis revisited. Bone 2009;44:11-6.

[44] Bonewald LF. The amazing osteocyte. J Bone Miner Res 2011;26:229-38.

[45] Seeman E. Bone quality: the material and structural basis of bone strength. J Bone Miner Metab 2008;26:1-8.

[46] Fratzl P, Gupta HS, Paschalis E, Roschger P. Structure and mechanical quality of the collagen-mineral nano-composite in bone. J Mater Chem 2004;14:2115-23.

[47] Fratzl P, Roschger P, Fratzl-Zelman N, Paschalis EP, Phipps R, Klaushofer K. Evidence that treatment with risedronate in women with postmenopausal osteoporosis affects bone mineralization and bone volume. Calcif Tissue Int 2007;81:73-80.

[48] Karasik D, Ferrari SL. Contribution of gender-specific genetic factors to osteoporosis risk. Ann Hum Genet 2008;72:696-714.

[49] Deng HW, Mahaney MC, Williams JT, Li J, Conway T, Davies KM, et al. Relevance of the genes for bone mass variation to susceptibility to osteoporotic fractures and its implications to gene search for complex human diseases. Genet Epidemiol 2002;22:12-25.

[50] Kanis JA, Oden A, Johnell O, De Laet C, Jonsson B. Excess mortality after hospitalisation for vertebral fracture. Osteoporos Int 2004;15:108-12.

[51] van Meurs JB, Schuit SC, Weel AE, van der KM, Bergink AP, Arp PP, et al. Association of $5^{\prime}$ estrogen receptor alpha gene polymorphisms with bone mineral density, vertebral bone area and fracture risk. Hum Mol Genet 2003;12:1745-54.

[52] Hoorn EJ, Rivadeneira F, van Meurs JB, Ziere G, Stricker BH, Hofman A, et al. Mild hyponatremia as a risk factor for fractures: the Rotterdam Study. J Bone Miner Res 2011:26:1822-8.

[53] Verbalis JG, Barsony J, Sugimura Y, Tian Y, Adams DJ, Carter EA, et al. Hyponatremiainduced osteoporosis. J Bone Miner Res 2010;25:554-63.

[54] Barsony J, Sugimura Y, Verbalis JG. Osteoclast response to low extracellular sodium and the mechanism of hyponatremia-induced bone loss. J Biol Chem 2011;286: 10864-75.

[55] Kirmani S, Christen D, van Lenthe GH, Fischer PR, Bouxsein ML, McCready LK, et al. Bone structure at the distal radius during adolescent growth. J Bone Miner Res 2009;24:1033-42.

[56] Nishiyama KK, Macdonald HM, Moore SA, Fung T, Boyd SK, McKay HA. Cortical porosity is higher in boys compared with girls at the distal radius and distal tibia during pubertal growth: an HR-pQCT study. J Bone Miner Res 2012;27:273-82.

[57] Seeman E. Structural basis of growth-related gain and age-related loss of bone strength. Rheumatology (Oxford) 2008;47(Suppl. 4):iv2-8.

[58] Parfitt AM. The two faces of growth: benefits and risks to bone integrity. Osteoporos Int 1994;4:382-98.

[59] Fratzl-Zelman N, Roschger P, Misof BM, Nawrot-Wawrzyniak K, Potter-Lang S Muschitz C, et al. Fragility fractures in men with idiopathic osteoporosis are associated with undermineralization of the bone matrix without evidence of increased bone turnover. Calcif Tissue Int 2011;88:378-87.

[60] Misof BM, Patsch JM, Roschger P, Muschitz C, Gamsjaeger S, Paschalis EP, et al Intravenous treatment with ibandronate normalizes bone matrix mineralization and reduces cortical porosity after two years in male osteoporosis: a paired biopsy study. J Bone Miner Res 2013. http://dx.doi.org/10.1002/jbmr.2035.

[61] Diderich KE, Nicolaije C, Priemel M, Waarsing JH, Day JS, Brandt RM, et al. Bone fragility and decline in stem cells in prematurely aging DNA repair deficient trichothiodystrophy mice. Age (Dordr) 2012;34:845-61.

[62] Nishimura G, Lausch E, Savarirayan R, Shiba M, Spranger J, Zabel B, et al. TRPV4associated skeletal dysplasias. Am J Med Genet C Semin Med Genet 2012;160C: 190-204.

[63] Scheller EL, Song J, Dishowitz MI, Hankenson KD, Krebsbach PH. A potential role for the myeloid lineage in leptin-regulated bone metabolism. Horm Metab Res 2012;44:1-5

[64] Xu ZP, Gao WC, Wang HP, Wang XH. Expression of transient receptor potential subfamily mRNAs in rat testes. Nan Fang Yi Ke Da Xue Xue Bao 2009;29:519-20.

[65] Lee H, Caterina MJ. TRPV channels as thermosensory receptors in epithelial cells. Pflugers Arch 2005;451:160-7.

[66] Chen X, Alessandri-Haber N, Levine JD. Marked attenuation of inflammatory mediator-induced C-fiber sensitization for mechanical and hypotonic stimuli in TRPV4 $^{-/-}$mice. Mol Pain 2007;3:31

[67] Wijchers PJ, Festenstein RJ. Epigenetic regulation of autosomal gene expression by sex chromosomes. Trends Genet 2011;27:132-40. 